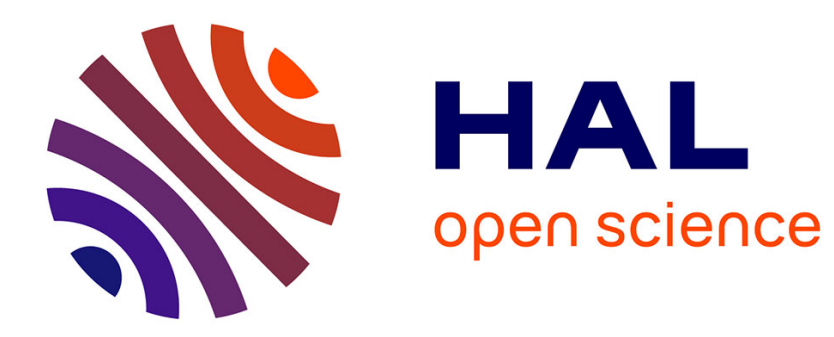

\title{
Properties of Arc Cathode Spots
}

B. Jüttner

\section{- To cite this version:}

B. Jüttner. Properties of Arc Cathode Spots. Journal de Physique IV Proceedings, 1997, 07 (C4), pp.C4-31-C4-45. 10.1051/jp4:1997404 . jpa-00255560

\section{HAL Id: jpa-00255560 https://hal.science/jpa-00255560}

Submitted on 1 Jan 1997

HAL is a multi-disciplinary open access archive for the deposit and dissemination of scientific research documents, whether they are published or not. The documents may come from teaching and research institutions in France or abroad, or from public or private research centers.
L'archive ouverte pluridisciplinaire HAL, est destinée au dépôt et à la diffusion de documents scientifiques de niveau recherche, publiés ou non, émanant des établissements d'enseignement et de recherche français ou étrangers, des laboratoires publics ou privés. 


\title{
Properties of Arc Cathode Spots
}

\author{
B. Jüttner
}

Humboldt-Universität zu Berlin and Max-Planck-Institute for Plasma Physics, Mohrenstrasse 41, 10117 Berlin, Germany

\begin{abstract}
Arc cathode spots operating by formation of surface-microplasmas are reviewed for discharges in vacuum and in gases. New experimental studies using advanced optical methods (image converter cameras and laser absorption techniques) reveal that the spot is composed of fragments with a size below $10 \mu \mathrm{m}$. In vacuum these are highly mobile, for copper on a time scale $<50 \mathrm{~ns}$. The motion and the rapid sequences of extinctions and re-ignitions determine the behavior of the whole spot. Cu-spots in vacuum exhibit displacements in times $<100$ ns. A tentative explanation of the spot movement is given on the base of the fragment dynamics. In gases the fragments are more separated than in vacuum. The ignition of fragments is discussed in the framework of recent studies on the glow-toarc transition in high pressure discharges. Finally, new mechanisms for enhanced field electron emission are mentioned.
\end{abstract}

\section{INTRODUCTION}

Trivially, in a gas discharge the areas of the electrodes are limited, so the cathodic region is necessarily finite. Frequently the discharges do not use the whole available surface, they contract to a more or less circular footpoint at the cathode. This contraction can be understood by processes in the gas plasma and in the space charge sheath that separates the plasma from the surface. In recent years considerable progress has been achieved in the understanding of gaseous arcs with hot cathodes [1-8]. Here the arc heats the cathode to temperatures sufficient to transfer the current by thermionic emission. While in the past the models were incomplete, necessitating arbitrary assumptions such as the minimum principle or empirical parameters such as the cathode fall, by including the non-stationary heat conduction in the cathode body the modern theories achieve a self-consistent description of the whole discharge system [1-7]. In this way, without using empirical parameters, spot radii can be determined, having values of $0.5-2 \mathrm{~mm}$, surface and plasma temperatures can be calculated, having values of 3000-4000 and 2-3 eV, respectively, and the cathode fall is obtained as $10-20 \mathrm{~V}[6,7]$. These values are in sometimes excellent agreement with the experiment [7], so it seems that the research has reached its final stage. At present, even 3D-calculations are possible [5] yielding still more exact data.

However, this comfortable situation does not hold for all kind of spots. With cold cathodes the current can no longer be transferred by thermionic emission. Also with hot cathodes there may arise transient situations where the temperature does not suffice. Then the discharge contracts to a submillimeter region. When the local energy transfer to the surface surpasses a certain limit the surface starts to evaporate. From the vapor a dense microplasma is formed, being highly non-stationary. The resulting cathode spots constitute a qualitatively new phenomenon, because they allow the transfer of virtually unlimited currents between discharge plasma and cathode at relatively small voltages $<50 \mathrm{~V}$, without external electrode heating, and for all conducting electrode materials.

The present paper restricts itself to such vapor-producing cathode spots. They are most common with cold cathodes, but can be found at hot cathodes, too. They occur in numerous applications: Electric arcs, sparks, welding devices, or switches. They are welcome in vacuum arc coating devices and ion sources, but a nuisance at inner walls of fusion machines or at the electrodes of gas discharge lamps. Their physical parameters are still subjected to sometimes vivid disputes, but it is not necessary to take care for the 
production of the spots, because they occur as a self-organizing phenomenon. This may be one of the reasons why the lack of understanding is widely tolerated. However, sometimes it is desirable but difficult to avoid them. There is hope to improve this situation by better knowledge.

The experimental difficulty is. due to the small size and the variability of the spots, the latter being controlled by surface effects. Theoretical problems arise by nonlinear feedbacks, nonstationary processes and poorly known material parameters at high temperatures and pressures. Modern optical methods yielding information with high spatial and time resolution and new theoretical concepts promise a more satisfactory explanation of the basic spot phenomena.

\section{DEFINITIONS AND PRINCIPLES OF THE THEORY}

The cathode spot is defined as an ensemble of heated surface and metal vapor plasma. Energy sources for surface heating are the Joule heat produced by the current and the impinging plasma particles (ions and energetic electrons). The hot surface emits electrons and evaporates metal, the latter constituting the medium for the spot plasma. Details of these processes are treated by numerous authors, the most recent presentation being given by Hantzsche [9]. The details are combined to complete theories on various levels: from the construction of possible existence areas for the spot parameters by Ecker [10] until the elaborated 1D-theory of Beilis [11].

The spot radius is determined by the size of the heated surface region. Leaving the cathode in direction of the anode one has a small ballistic zone defined by the Debye length (space charge sheath). Here the cathode fall is situated $(15-20 \mathrm{~V})$ that forms the emitted electrons to an energetic beam, and here the plasma ions gain the main part of the energy that is transmitted to the surface. Electrons and plasma ions cross this zone without suffering collisions. Directly at the surface the evaporated atoms have a uni-directional velocity distribution. It is transformed to a shifted Maxwellian distribution at the end of the heavy particle relaxation zone, extending beyond the ballistic zone. Still more distant from the surface ends the electron beam relaxation zone where the emitted electrons are thermalized by collisions. It is at the end of this zone that the vapor is ionized forming a dense plasma. The plasma then expands, in vacuum up to the anode, in gases up to some $\mathrm{mm}$ in dependence on the gas pressure (Drouet and Meunier [12]).

Relevant equations are (Beilis [11, 13]): for the plasma the Saha-equation, the energy balance of the electrons and the equations of state; for the evaporated atoms the Langmuir-equation and the conservation of mass; and for the surface the energy balance, the thermo-field emission and the electric field, the last from the Poisson-equation.

Typically for this kind of theories, the time enters via the surface heating, assuming that non-stationary heat conduction is the slowest process that governs the development [10]. Beilis [13] calculates the spot parameters as a function of time without specifying a fixed time value. Fig. 1 gives an example for the plasma density (electron density) and the spot radius. In the time range 50 $\mathrm{ns}$ to $1 \mathrm{~ms}$ the density decreases from $4 \times 10^{26} \mathrm{~m}^{-3}$ to $1 \times 10^{26} \mathrm{~m}^{-3}$ whereas the radius increases from 16 to $56 \mu \mathrm{m}$ (correspondingly, the current density decreases from $5 \times 10^{10} \mathrm{~A} / \mathrm{m}^{2}$ to $4 \mathrm{x}$ $10^{9} \mathrm{~A} / \mathrm{m}^{2}$ ). In the same time span, the surface temperature decreases from $4600 \mathrm{~K}$ to $4000 \mathrm{~K}$ and the electric field from $4 \times 10^{9} \mathrm{~V} / \mathrm{m}$ to $1.3 \times 10^{9}$ $\mathrm{V} / \mathrm{m}$.

In practice, evaporating spots are basically non-stationary. They are born during a formation time, change

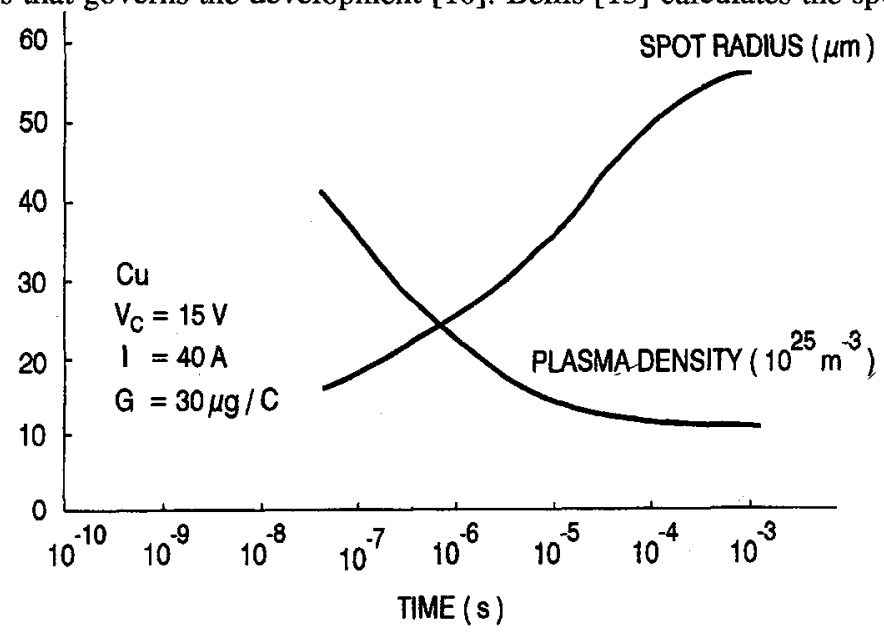

Fig. 1: Spot radius and plasma density as a function of time after Beilis [13] 
their size during a residence time, and then they are displaced. Any displacement of the discharge to a cold surface location means the end of the spots life and the formation of a new spot, because heating and evaporation must start again. During several decades of spot research, the boundaries given by the formation and the residence time are displaced to smaller values, in fig. 1 to the left (with some random component).

A somewhat different approach is proposed by Mesyats [14]. According to his model the spot operates on a sequence of nanosecond acts. Delivering quickly an energy amount of about $10^{7} \mathrm{~J} / \mathrm{kg}$ into a microscopic surface volume (corresponding to $10^{10}-10^{11} \mathrm{~J} / \mathrm{m}^{3}$ ), a burst of ionized matter and of emitted electrons occurs. The duration of this burst and the amount of ejected material little depend on the means of energy deposition and the material. So the spot processes are divided in nanosecond periods having some kind of fundamental character. Mesyats called them ECTONS ("Explosive Center"). If the energy is deposited by Joule heating of the surface with a current density $j$, the formation time $t_{f}$ is obtained from

$$
\int_{0}^{t_{f}} j^{2} d t=h_{m}
$$

The value of $h_{m}$ is nearly constant, amounting to $1.8 \times 10^{17} \mathrm{~A}^{2} \mathrm{~s} \mathrm{~m}^{-4}$ for $\mathrm{W}$ and to $4.1 \times 10^{17} \mathrm{~A}^{2} \mathrm{~s} \mathrm{~m}^{-4}$ for $\mathrm{Cu}$. It is clear that in this case $\mathrm{j}$ must surpass $10^{12} \mathrm{~A} / \mathrm{m}^{2}$ to reach nanosecond formation times. Relation (1) is known from the physics of exploding wires. Already Rothstein [15] suggested the analogy of the spots with exploding wires, but Mesyats and his colleagues were able to derive quantitative expressions for spot size, surface temperature, plasma density, erosion rate and plasma expansion velocity. Compared to fig. 1 , the values are situated at the left-hand side where Beilis stopped his calculation.

Knowing the time scale of the spot processes, one can decide which theoretical conception is valid. One has to deal with the question: is the spot a microsecond or a nanosecond phenomenon? The answer should be given by the experiment as discussed in the following sections.

\section{SPOTS IN VACUUM}

\subsection{Experiments with the emitted light}

Registering the emitted light by photographic methods seems to be the most straightforward way to measure spot size and time constants, especially in vacuum where the spot is the only light source. However, as shown by Hantzsche et al. [16], in vacuum the plasma expansion imposes a limit of about $10 \mu \mathrm{m}$ to the spatial resolution. During the radiative lifetime of excited states the particles move in an average over distances $\geq 10 \mu \mathrm{m}$, thus blurring the spot appearance. This effect hides spot displacements over distances $<10 \mu \mathrm{m}$ and, therefore, constitutes also a limit to the time measurement. Using continuum radiation the effect is absent, but then the intensity of the light does not suffice for nanosecond exposure times. So the results with the total light presented in the following give but upper limits of time and size.

In $[17,18]$ arc spots were produced at the rounded end of cylindrical cathodes having diameters of $0.3-0.5$ $\mathrm{mm}$. The current was $50-100 \mathrm{~A}$, the discharge duration about $200 \mu \mathrm{s}$. The surfaces were free from contamination layers (oxides, hydrocarbons), the residual gas pressure amounted to $10^{-7}$ Pa. $1-100 \mu$ s after arc ignition the cathode was photographed by a high speed image converter camera (IMACON 468) via a long distance microscope (QUESTAR QM 1) having a nominal resolution of $3 \mu \mathrm{m}$. Fig. 2 shows

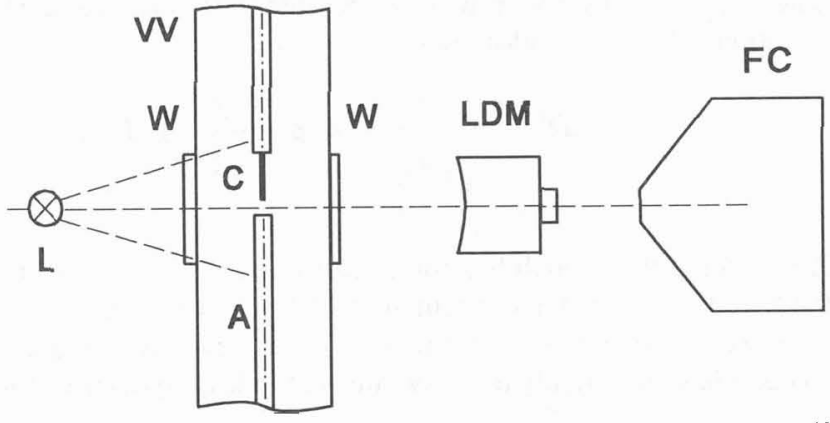

Fig. 2: Experimental setup from [17, 18]. C-cathode, A-anode, VVvacuum vessel, W-sapphire windows, L-lamp, LDM-long distance microscope, FC-framing camera 
the schematic of the device. The camera has eight channels that can freely be programmed in the time range $10 \mathrm{~ns}-1 \mathrm{~ms}$. In a later version, the eighth channel was exchanged for a streak unit allowing to continuously observe the spot displacement. If not stated otherwise, the arc current amounted to $70 \mathrm{~A}$, the electrode material was copper.

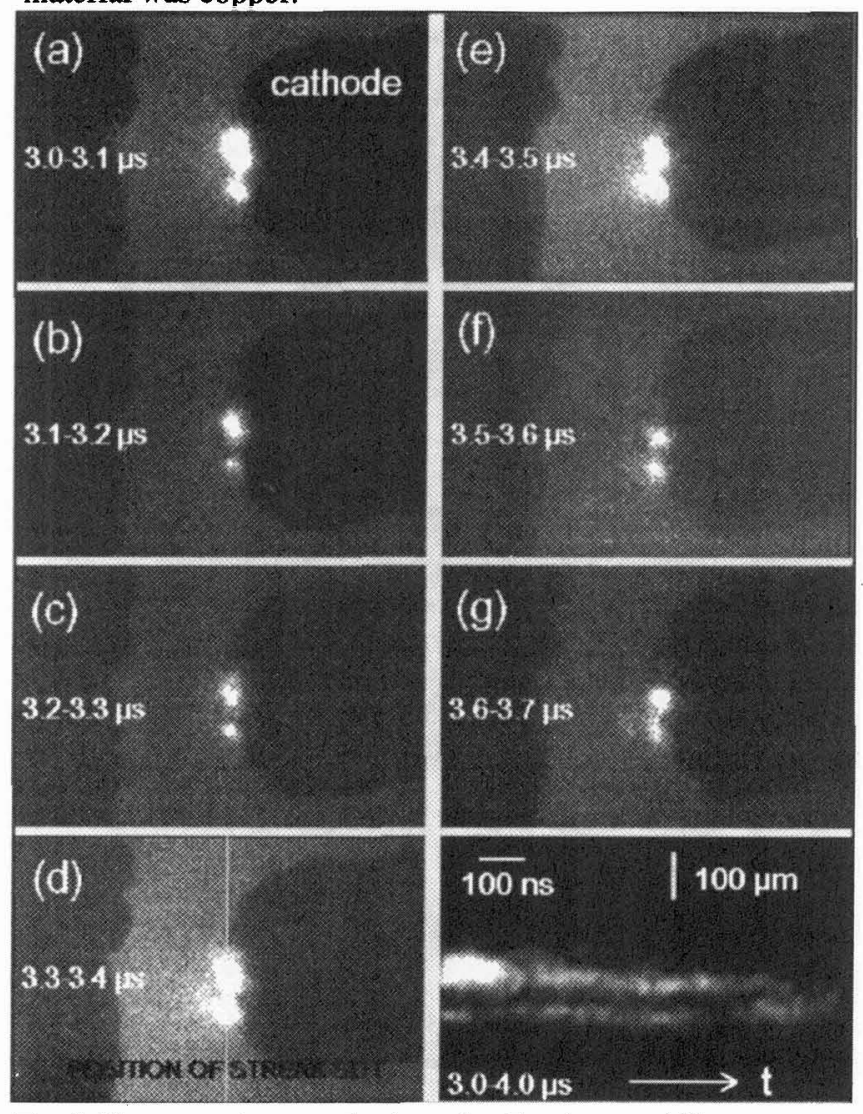

Fig. 3: Vacuum arc between Cu-electrodes. Framing time $100 \mathrm{~ns}$, no pause between the frames, streak sweep $1 \mu s$
Fig. 3 shows a picture taken $3 \mu$ s after arc ignition, with a framing time of $100 \mathrm{~ns}$, no pause between the frames, and a streak sweep of $1 \mu \mathrm{s}$. Two spots can be seen in front of the cathode that seem to be stationary during $1 \mu$ s. However, with a certain probability positional changes can be found in the submicrosecond range, especially when looking with higher magnification. This can be seen in fig. 4 where eight frames were used to display an arc $15 \mu \mathrm{s}$ after ignition (framing time $100 \mathrm{~ns}$, no pause between the frames). A single spot appears somewhat distant from the cathode apex, having clear internal structures that change in times $\leq 100 \mathrm{~ns}$. In the following these structures will be called fragments. Their apparent diameter is $10-20 \mu \mathrm{m}$. The fragments seem to periodically attract each other. Merging of some of the fragments leads to increased brightness $[17,18]$. Fig. 5 displays the signal of a fast photodiode showing brightness peaks with intervals of about $15 \mathrm{~ns}$ (for $\mathrm{Cu}$ ). When adding the streak channel to the frames one observes that during this dynamics the spot center is displaced. Fig. 6 gives an example with only $50 \mathrm{~ns}$ framing time. Finally, fig. 7 shows a sequence of frames where two spots distinctly changed their relative position within $50 \mathrm{~ns}$. For titanium, such changes could even be found during $20 \mathrm{~ns}$ [17].

Immobile spots as in fig. 3 do not represent a different species. Because the displacement occurs at random, for a given direction displacement zero is most probable. Fig. 8 shows the probability for displacements in $y$-direction within time intervals $t=100 \mathrm{~ns}, 200 \mathrm{~ns}$, and $500 \mathrm{~ns}$. Already for $\mathrm{t}=100 \mathrm{~ns}$ the distributions obey the random walk law

$$
W(Y) d Y=\frac{1}{\sqrt{\pi\left\langle R^{2}\right\rangle}} \exp \left(-\frac{Y^{2}}{\left\langle R^{2}\right\rangle}\right) d Y, \quad \frac{\left\langle R^{2}\right\rangle}{t}=\text { const. }
$$

$W(Y) d Y$ being the probability for a displacement between $Y$ and $Y+d Y$ and $\left\langle R^{2}>\right.$ the mean square value of the two-dimensional displacement, $\left(\left\langle R^{2}\right\rangle=2\left\langle Y^{2}\right\rangle\right)$ ).

Hence, the spot displacement takes place on a submicrosecond timescale. Sometimes it is argued that the spots behave differently on broad area cathodes, especially at higher currents where spot grouping leads to stationary scenarios. To test this, in ref. [13] the movement was analysed on copper cathodes of $65 \mathrm{~mm}$ diameter with currents up to $1.5 \mathrm{kA}$. Fig. 9 shows a streak of spots at $980 \mathrm{~A}$. Table 1 gives the random walk data from this experiment together with the values according to fig. 8 for $70 \mathrm{~A}$. 


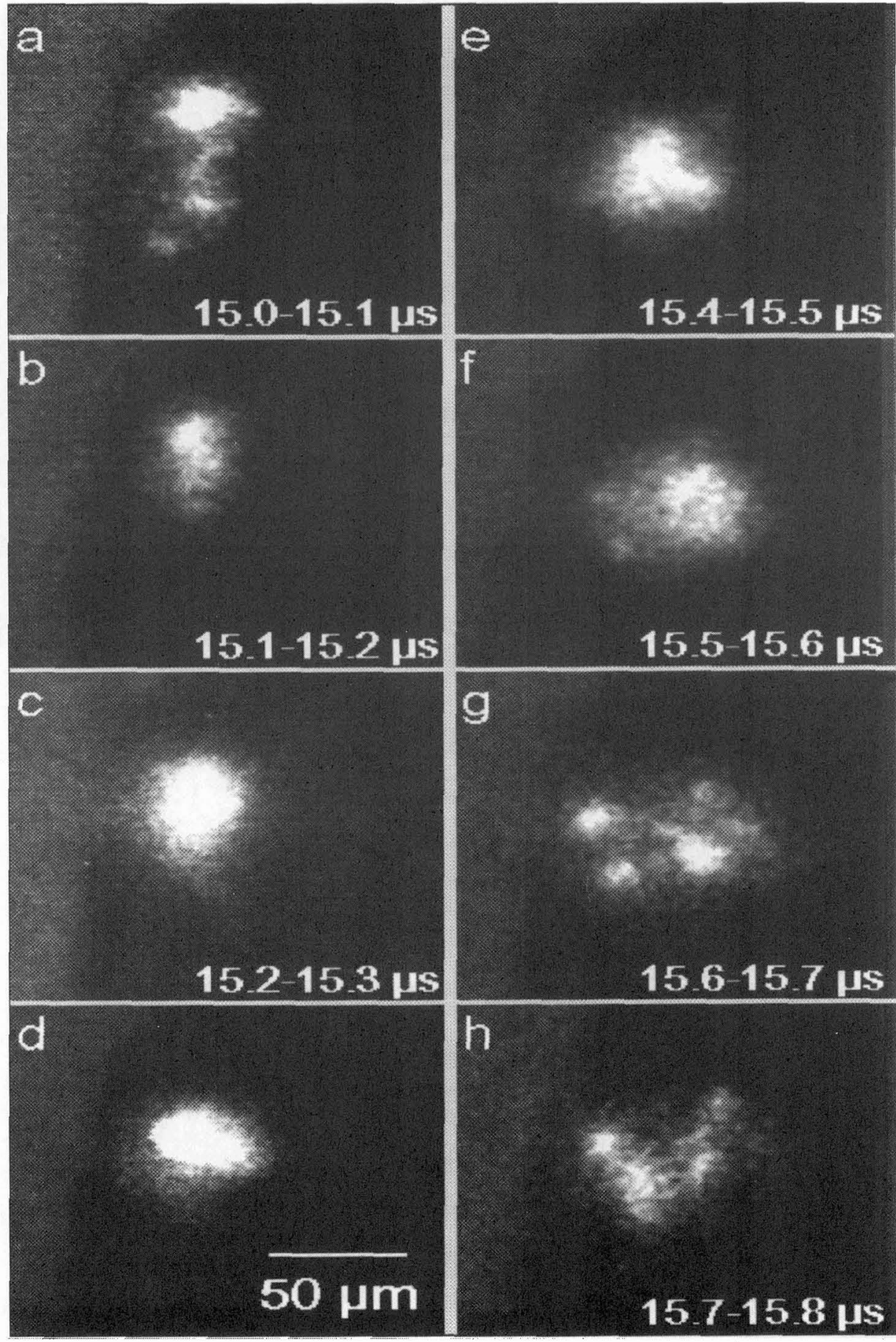

Fig. 4: Are spot with inner fragments. Frame exposure time $100 \mathrm{~ns}$, no pause between the frames, delay to ignition $15 \mu \mathrm{s}$. $\mathrm{Cu}, 70 \mathrm{~A}$. 


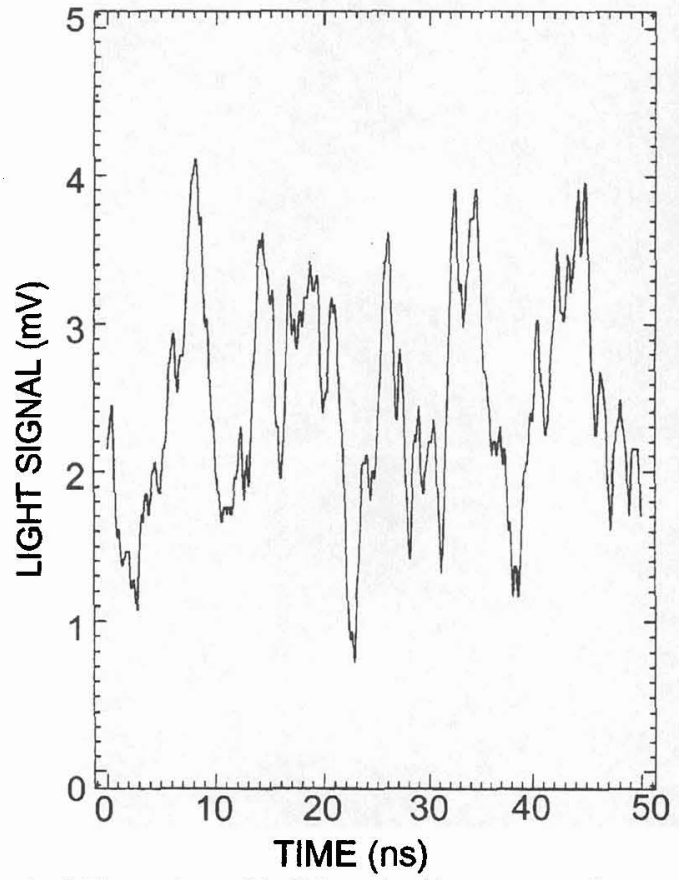

Fig. 5: Fluctuations of the light emitted by an arc spot in vacuum

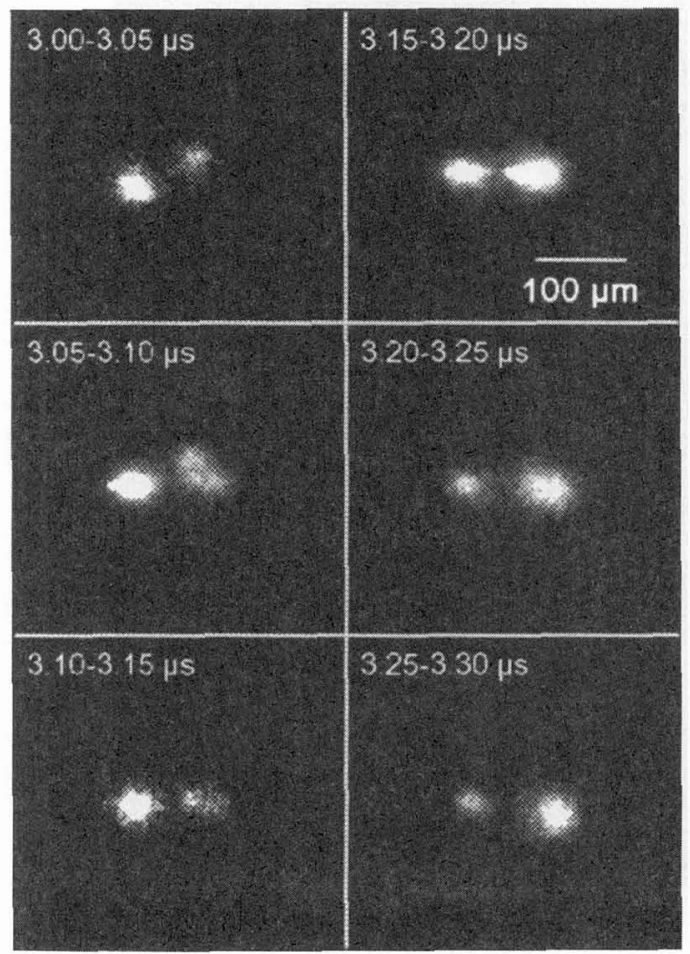

Fig. 7: Positional changes of two cathode spots on $\mathrm{Cu}$. Frame exposure time $50 \mathrm{~ns}$, no pause between the frames

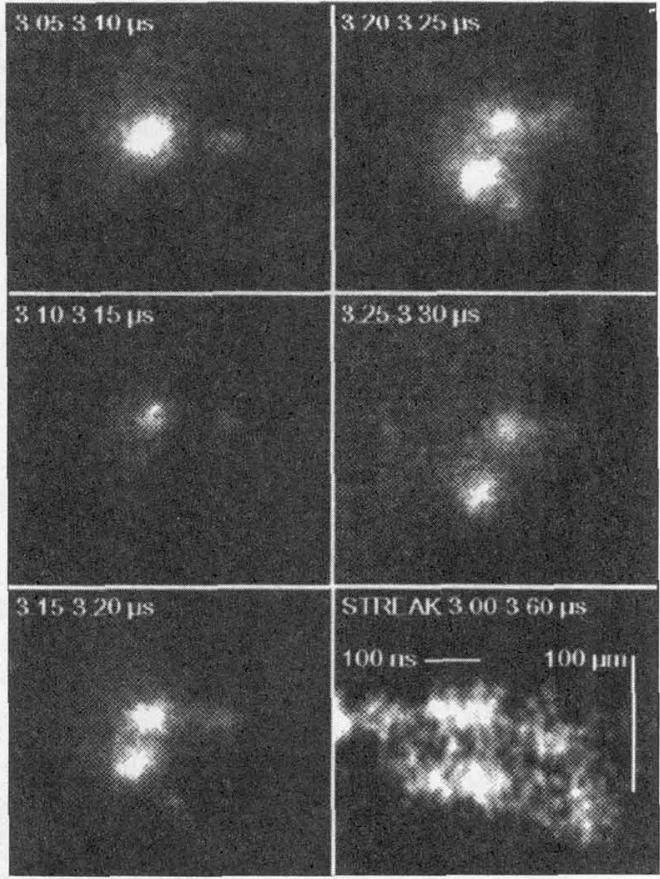

Fig. 6: Submicrosecond spot displacement. Frame exposure time 50 ns, no pause between the frames, streak sweep $600 \mathrm{~ns}$, delay to ignition $3 \mu \mathrm{s}$. $\mathrm{Cu}, 70 \mathrm{~A}$

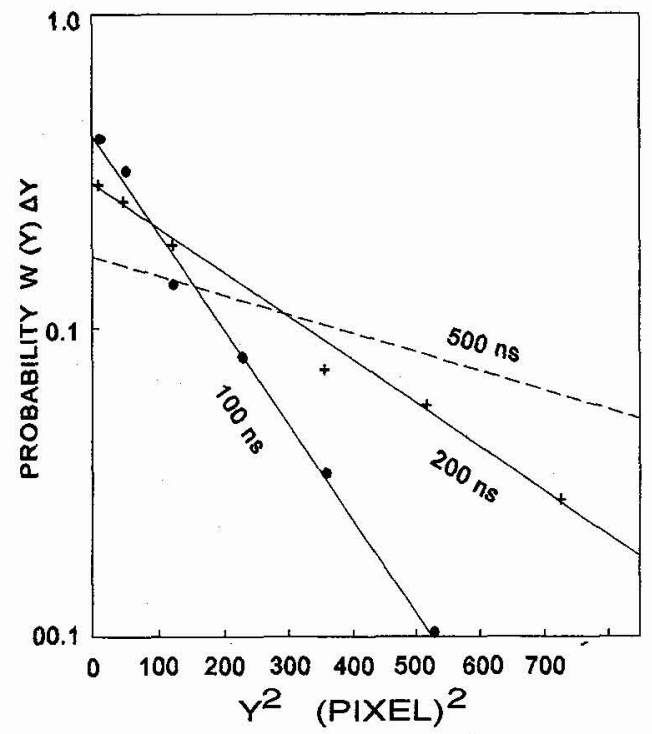

Fig. 8: Probability for one-dimensional spot displacements for time intervals of $100 \mathrm{~ns}, 200 \mathrm{~ns}$ and $500 \mathrm{~ns}$. One pixel equals 1.2 $\mu \mathrm{m}[18]$ 


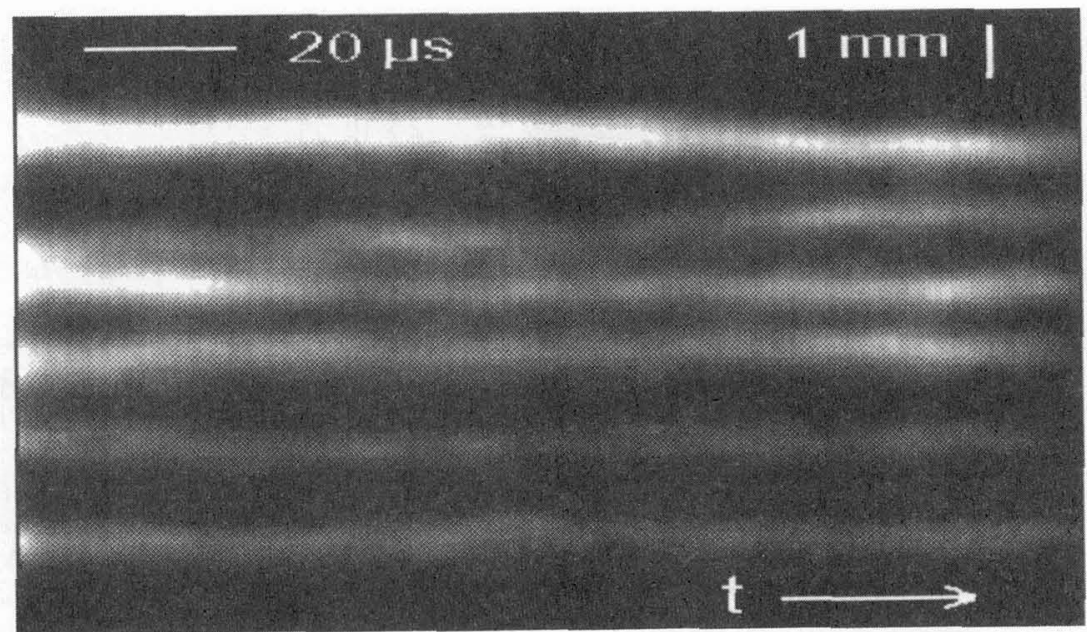

Fig. 9: Streak of arc cathode spots on a Cu-cathode or $65 \mathrm{~mm}$ diameter. Total current $980 \mathrm{~A}, 3 \mathrm{~ms}$ after ignition [13]

Table 1: Random walk data for extended and small Cu-cathodes

$N$-number of events, $t$-observation time, $\left\langle R^{2}>\right.$-mean square value of two-dimensional displacement

\begin{tabular}{|c|c|c|c|c|c|}
\hline $\begin{array}{c}\text { Cathode Diameter } \\
(\mathrm{mm})\end{array}$ & Reference & Current (A) & $\mathrm{N}$ & $\mathrm{t}(\mu \mathrm{s})$ & $\begin{array}{c}<\mathrm{R}^{2}>/ \mathrm{t} \\
\left(10^{-3} \mathrm{~m}^{2} / \mathrm{s}\right)\end{array}$ \\
\hline \hline 65 & {$[13]$, fig. 9} & $40-100$ & 56 & 25 & $1.3 \pm 0.5$ \\
\hline 65 & {$[13]$, fig. 9} & $150-1500$ & 343 & 25 & $1.0 \pm 0.3$ \\
\hline 65 & {$[13]$, fig. 9} & $40-1500$ & 229 & 75 & $1.0 \pm 0.3$ \\
\hline 0.47 & {$[18]$, fig. 8} & 70 & 145 & 0.1 & $2.2 \pm 0.6$ \\
\hline 0.47 & {$[18]$, fig. 8} & 70 & 310 & 0.2 & $2.3 \pm 0.6$ \\
\hline 0.47 & {$[18]$, fig. 8} & 70 & 725 & 0.5 & $2.2 \pm 0.6$ \\
\hline
\end{tabular}

Although in table 1 the ratio of the mean square displacement $\left\langle\mathrm{R}^{2}\right\rangle$ to the measuring time is somewhat smaller for broad area cathodes, the order of magnitude is the same, thus no principal change of the spot behavior can be stated.

\subsection{Experiments with absorbed light}

Absorption of laser light yields pictures of the spot plasma having advantages over the technique using the emitted light: the broadening of the image by the plasma expansion is minimized [16], and the hot surface cannot contribute. Also, with short laser pulses the exposure time can be $<1$ ns. Fig. 10 gives an example for a $\mathrm{Cu}$-arc of $90 \mathrm{~A}$, taken $232 \mathrm{~ns}$ after ignition with an exposure time of $0.4 \mathrm{~ns}$ [19]. Structures with a size down to $5 \mu \mathrm{m}$ can be seen. From the absorption coefficient, in [19] electron densities $\geq 6 \times 10^{26}$ $\mathrm{m}^{-3}$ have been estimated. No principal changes have been observed when delaying the picture by up to 50 $\mu$ after ignition.

Vogel [20] registered density profiles after Abel-inversion as shown in fig. 11. A long-distance microscope with a resolution of about $1 \mu \mathrm{m}$ was used, thus showing more details as in $[17,18]$. Obviously 


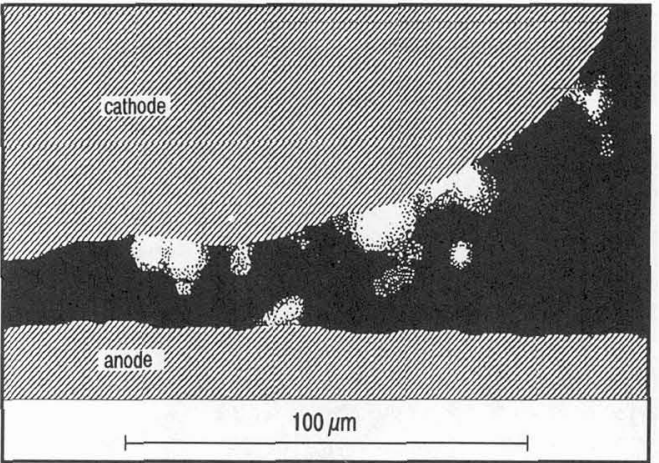

Fig. 10: Absorption picture of Cu-spots, $90 \mathrm{~A}$, taken $232 \mathrm{~ns}$ after ignition with $0.4 \mathrm{~ns}$ exposure time [19]

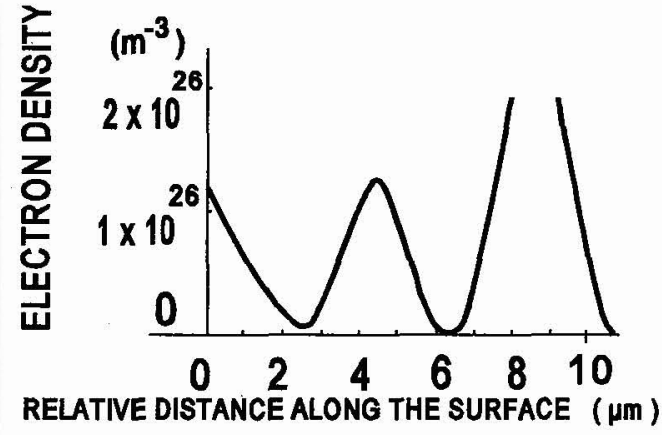

Fig. 11: Linear scan of the electron density of a $\mathrm{Cu}$-spot in vacuum obtained from absorption profiles taken $18 \mathrm{~ns}$ after ignition with $0.1 \mathrm{~ns}$ exposure time. Current $9 \mathrm{~A} \mathrm{[20]}$

the figure depicts the fragment structure at an early phase. Three fragments are observed having a half-width of 3-5 $\mu \mathrm{m}$ and distances of about $5 \mu \mathrm{m}$. With the emitted light they would have appeared as a single spot.

\subsection{Contradictions}

As can be seen in the preceding sections, the fragments of vacuum arc spots are small and fast as well. There are, however, papers being at variance to this statement. Siemroth et al. [21] studied copper arc spots in vacuum at currents of about 3-5 kA with a high speed framing camera. With such currents numerous spots and fragments are present. The fragments (the authors called them subspots) were found to be small, having a half-width of about $10 \mu \mathrm{m}$ [21], thus one might assume that they are similar to those depicted in fig. 4. However, Siemroth et al. found little changes for times $<10 \mu \mathrm{s}$. The present author believes that this is due to the evaluation method used in ref. [21]. Siemroth et al. exposed the four framing channels of their camera to the same event using increasing exposure times for each channel and suggesting that the spot movement will broaden the picture if the exposure time surpasses the residence time. Fig. 12 shows the luminous fragment profile for exposure times of $10 \mathrm{~ns}, 100 \mathrm{~ns}, 1 \mu \mathrm{s}$, and $10 \mu \mathrm{s}$. Obviously the profile width increases when the time exceeds $10 \mathrm{~ns}$, but probably the background must be subtracted, being itself a function of the exposure time.

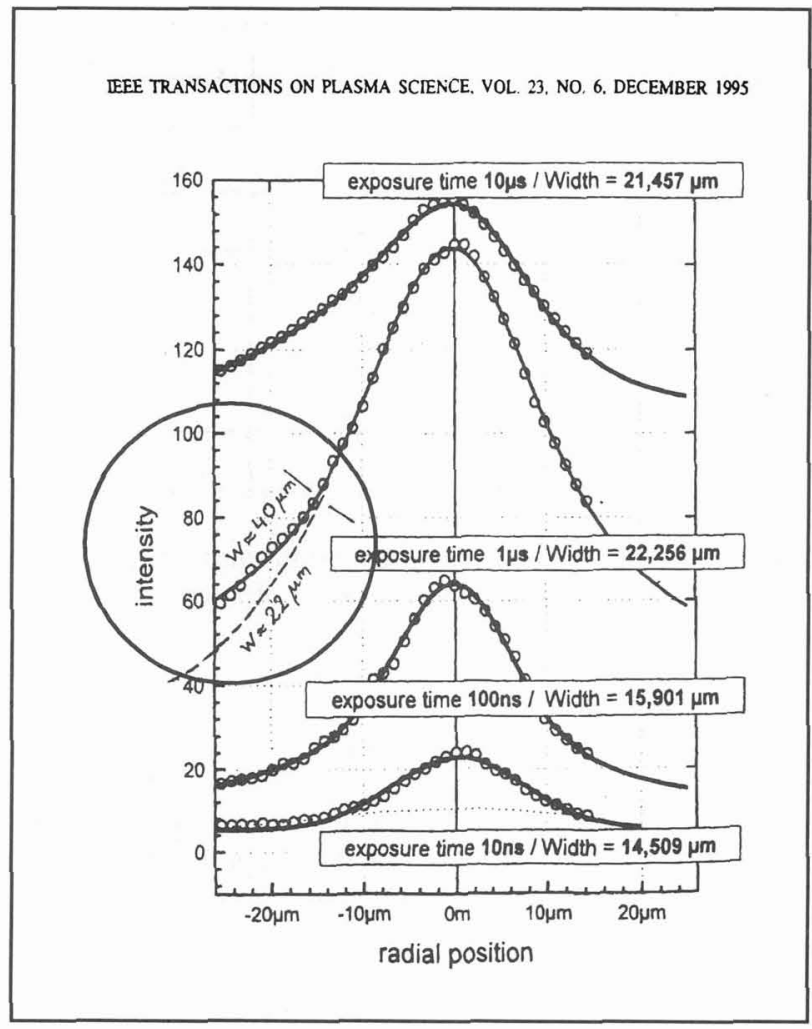

Fig. 12: Luminous fragment profiles at different exposure times after Siemroth et al. [21] 
This background arises from the presence of numerous spots at high current. Although the subtraction might produce arbitrary profile forms and widths, it seems natural to look for a Gaussian profile. In [21] this was possible for the center of the measured curves, yielding half-widths of about $20 \mu \mathrm{m}$ for all exposure times. However, this does not hold for the wings, as indicated in the circle at the $1 \mu \mathrm{s}$-curve (drawn by the present author). Fitting the wing by a Gaussian curve would yield the half-width of about twice as much. Thus, as pointed out in ref. [18], the method underestimates the movement because of the neglection of the outer zones of the luminous profile. The invariability of the deduced half-width led Siemroth et al. to the conclusion that $<\mathrm{R}^{2}>/ \mathrm{t}<10^{-5} \mathrm{~m}^{2} / \mathrm{s}$, in contrast to $\mathrm{Tab}$. 1 . Using the wings of the profiles, much higher values would have been obtained. Hence, the difference between [18] and [21] might be due to different evaluation methods rather than to different phenomena.

\section{SPOTS IN GASES}

With the same system as described in figs. 2-7, preliminary experiments have been carried out at atmospheric pressure. In these cases the bright gas plasma covered the whole apex of the cathodes, so with the emitted light cathode spots could only be observed at the boundary of this plasma. Fig. 13 shows this for air and fig. 14 for argon. Numerous isolated spots can be seen with a size $\leq 5 \mu \mathrm{m}$, i. e. at the limit of the spatial resolution. Such structures are found occasionally even at hot cathodes as demonstrated in fig. 15 for a high pressure sodium lamp.

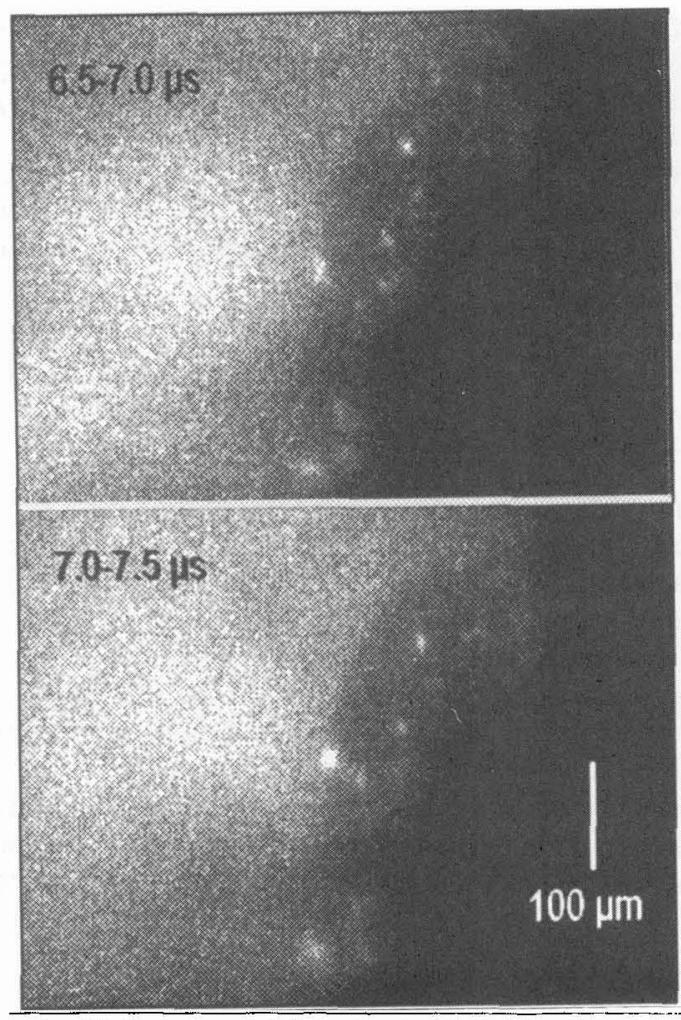

Fig. 13: Spots in air, $6.5 \mu \mathrm{s}$ after ignition, $0.5 \mu \mathrm{s}$ exposure time. $\mathrm{Cu}, 70 \mathrm{~A}$

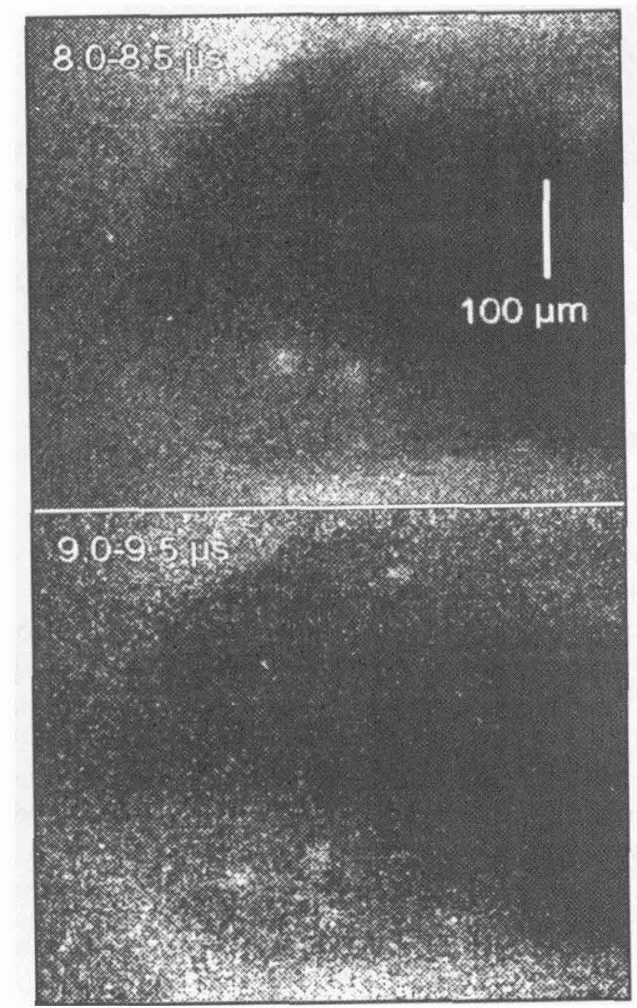

Fig. 14: Spots in argon, at atmospheric pressure, $8 \mu \mathrm{s}$ after ignition, $0.5 \mu$ s exposure time. $\mathrm{Cu}, 70 \mathrm{~A}$ 

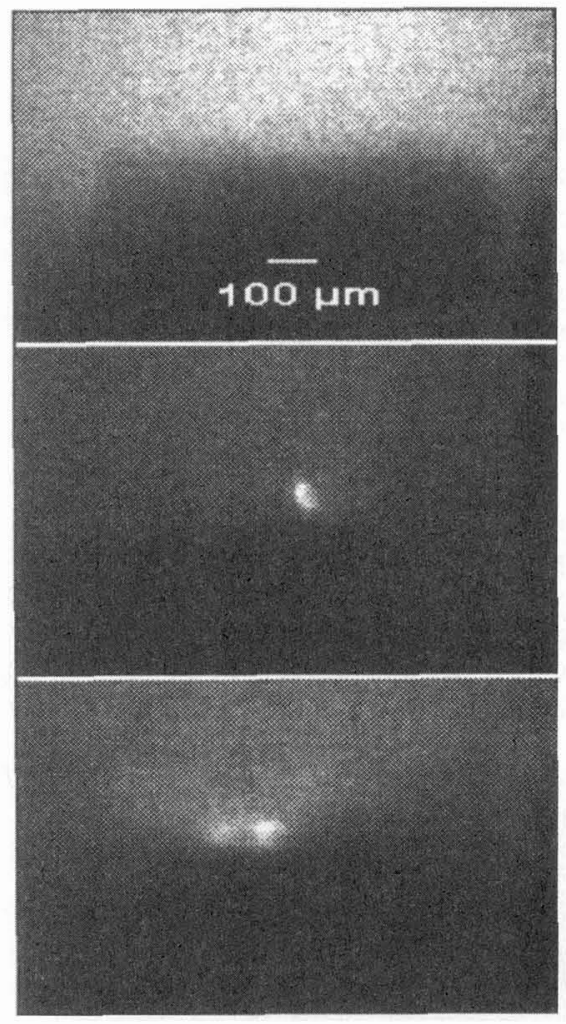

Fig. 15: Spots at the hot cathode of a high pressure sodium lamp after about one hour burning at $50 \mathrm{~Hz}$ Snapshots in different half-cycles, exposure time $2 \mu \mathrm{s}$

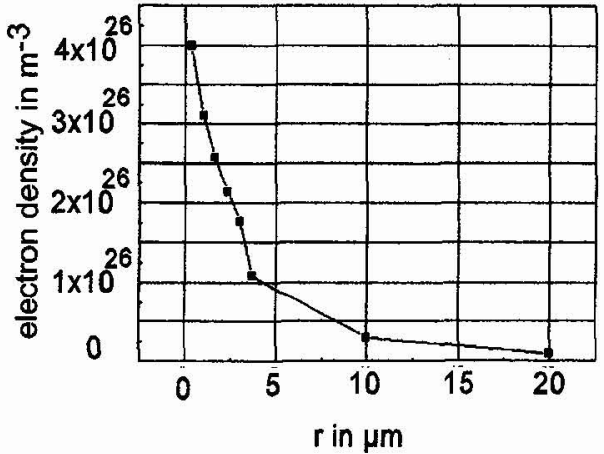

Fig. 16: Electron density profile obtained from laser absorption in atmospheric air. $\mathrm{Cu}, 9 \mathrm{~A}$, exposure time $0.1 \mathrm{~ns}$, delay to ignition $9 \mathrm{~ns}$ [22]

The absorption technique avoids the interference of the gas plasma. Fig. 16 shows a density profile for a $\mathrm{Cu}$-spot in air obtained by Vogel [22]. The half-width amounts to about $3 \mu \mathrm{m}$, the density reaches $4 \times 10^{26} \mathrm{~m}^{-3}$. At the cathode of pseudo-sparks, Frank et al. [23] found spots $<15 \mu \mathrm{m}$ with a minimum density of $10^{27} \mathrm{~m}^{-3}$.

\section{CONSEQUENCES}

In vacuum the emitted light yields information on the time scales. In our measurements for the fragments and the whole spot the time constants are definitely $<50 \mathrm{~ns}$ and $<100 \mathrm{~ns}$, respectively. These short times do no refer to an initial phase followed by a.more stationary regime, but they describe the whole phenomenon. Delaying the frame pictures by $10 \mathrm{~ns}$ through $100 \mu \mathrm{s}$ did not result in longer time constants at higher delays. Thus, the ECTONconception formulated by Mesyats [14] seems to be near the truth.

Absorption pictures of vacuum spot fragments indicate diameters of less than $5 \mu \mathrm{m}$. So the fragment plasmas are smaller than the surface craters found after the discharges. It seems plausible that the small spots in gases are of similar nature as the fragments in vacuum. The difference is: they are not free to move and to merge, and they can carry currents $<1 \mathrm{~A}$. Because of the limited expansion of the spot plasma, in our experiments spots in gases appear small also in the emitted light. Tab. 2 compares spots in vacuum and in gases. Probably the fragments in vacuum are still composed structures, while at atmospheric pressure one observes the most elementary spot components. 
Table 2: Comparison of $\mathrm{Cu}$-arc spots in vacuum and in gases (figs, 4, 6, 7, 10, 13, 14)

\begin{tabular}{||l||c|c|}
\hline \multicolumn{1}{|c|}{ FEATURE } & AIR, ARGON & VACUUM \\
\hline $\begin{array}{l}\text { current per } \\
\text { fragment }\end{array}$ & $<1 \mathrm{~A}$ & $5-10 \mathrm{~A}$ \\
\hline $\begin{array}{l}\text { apparent plasma } \\
\text { diameter }\end{array}$ & $\leq 5 \mu \mathrm{m}$ & $10-20 \mu \mathrm{m}$ \\
\hline $\begin{array}{l}\text { distance between } \\
\text { fragments }\end{array}$ & $50-100 \mu \mathrm{m}$ & $10-50 \mu \mathrm{m}$ \\
\hline displacement & $\begin{array}{l}\text { oscillation and rotation in areas of } \\
50-100 \mu \mathrm{m} \text { diameter within times }< \\
500 \mathrm{~ns}\end{array}$ & $\begin{array}{l}\text { random movement within } \\
\text { times }<100 \mathrm{~ns}: \\
\mathrm{R}^{2} / \mathrm{t} \approx 10^{-3} \mathrm{~m}^{2} / \mathrm{s}, \quad \mathrm{v} \propto 1 / \sqrt{\mathrm{t}}\end{array}$ \\
\hline
\end{tabular}

The division into fragments helps the spot to survive: if one fragment dies the other fragments take over the current until a new fragment is formed. Also, the spot motion can be explained by the action of the fragments. The Lorentz-force causes them to attract each other. The framing pictures (comp. fig. 4) indicate a scenario as depicted in fig. 17: The fragments move into the spot center. When they are close together, an instability occurs like an explosion, accompanied by increased brightness (comp. fig. 5). This results in the formation of new fragments at the periphery, and the cycle starts again. Here one could speculate on the reason for the spot movement: If one fragment dies before merging, the configuration becomes non-symmetric and the center of gravity of the spot is displaced (in fig. 17 to the right). An external magnetic field will tend to remove a fragment in forward direction, causing to displace the remainder in a retrograde way. A gas reduces the interaction between the fragments and can, therefore, reverse the direction. This idea, however, must be examined by further experiments.

\section{SPOT IGNITION}

If the spots life is a sequence of nanosecond acts of birth and death of the constituents, the question arises how new fragments can be ignited. Directly in the spot this process is difficult to investigate. There are, however, some recent works that study ignition processes in much detail $[24,25]$. In these experiments, a plasma is brought into contact with a negatively biased electrode, thus observing the processes preceding the spot formation. The problem is related to the question of glow-to-arc transition.

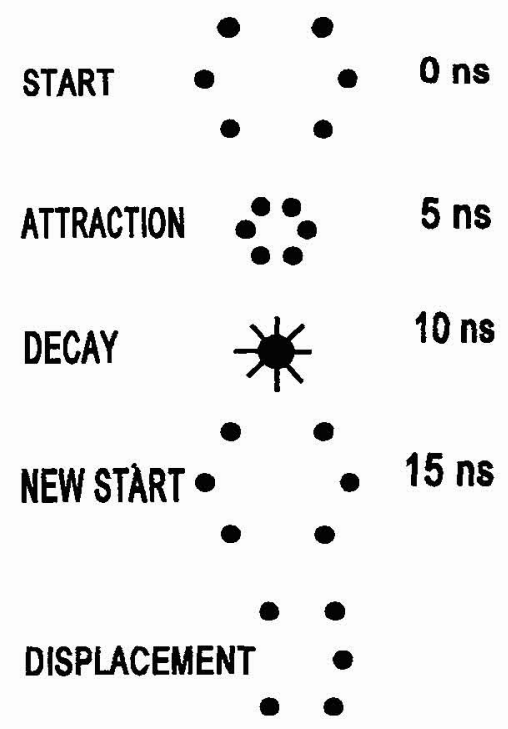

Fig. 17: Schematic of fragment dynamics and spot displacement

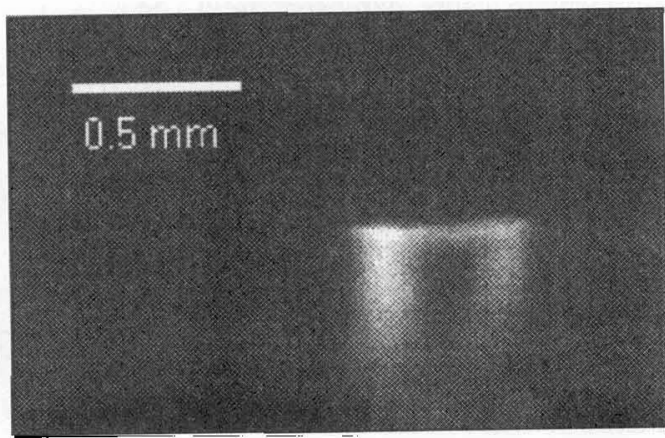

Fig. 18: Luminous cathodic layer preceding spot formation [24]. Cu-electrode, argon at atmospheric pressure, exposure time $100 \mathrm{~ns}$ 
Mentel and co-workers [24, 25] found that at first a luminous cathodic layer is formed having a width of 75-200 $\mu \mathrm{m}$. Fig. 18 gives an example. The contraction to spots is already indicated at two locations. In this phase, a current up to some $100 \mathrm{~mA}$ is flowing that exceeds the ion saturation current from the plasma. (Such precurrents have also been found at negatively biased electrodes in a tokamak [26, 27]). After some time the spots start to operate as bright localized structures. As fig. 19 shows, at the surface one finds a homogeneously changed region (due to the plasma layer), intersected by craters (due to the spots) [25].

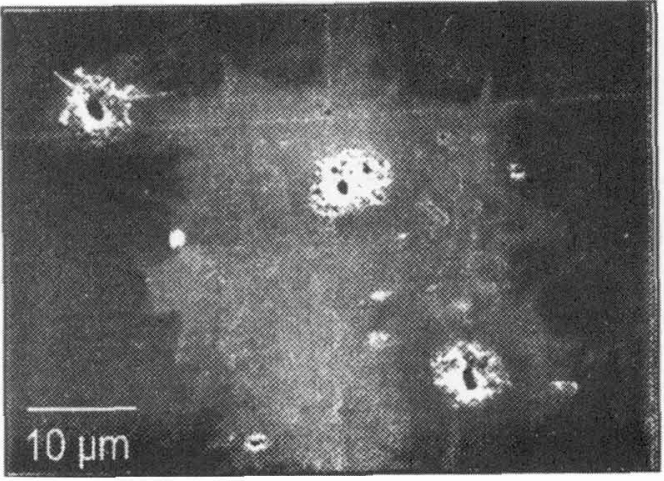

Fig. 19: Erosion of a Cu-cathode by a predischarge followed by a short arc [25]

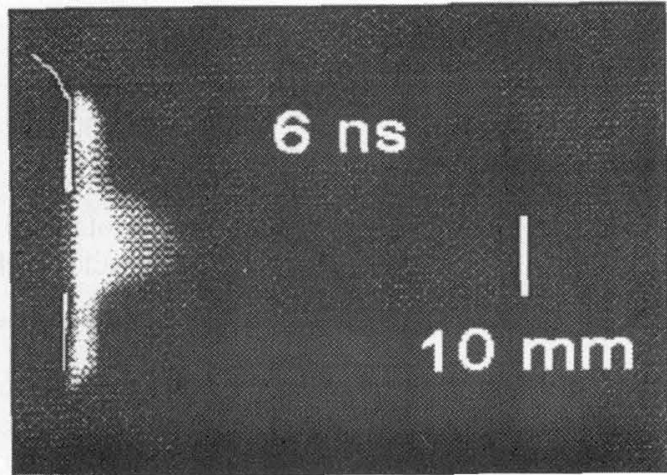

Fig. 20: Luminous sheath at the cathode as a precursor to spot formation in high pressure discharges [28]

Luminous sheaths have also been found at the cathode of excimer lasers [28] as demonstrated in fig. 20. Korolev and Mesyats [29] reported that the duration of such predischarges decreases with increasing pressure. It decreases also with increasing bias voltage. Fig. 21 compiles results from [24, 27-29]. Near a cathode spot, where the pressure may reach values $>10$ bar, the times will be $<5 \mathrm{~ns}$, so the delay of fragment formation can be sufficiently small.

Elaborated theories have been published by Belasri and co-workers [30] and Simon and Bötticher [31]. According to these works, the electric field at the cathode may reach values in excess of $10^{8} \mathrm{~V} / \mathrm{m}$ at the stage of sheath formation. From experiments on vacuum breakdown it is known that such fields are sufficient to cause explosive field emission at the surface.

Regarding the field emission, two new ideas have been emerged in recent years: (i) Jimenez and coworkers [32] were able to show that in vacuum the combination of micrometer surface structures with submicrometer protrusions causes local field enhancement by factors $>100$. Such structures will be intense emitters in the electric field of the luminous cathodic layer. (ii) The individual field of plasma ions approaching the surface can enhance

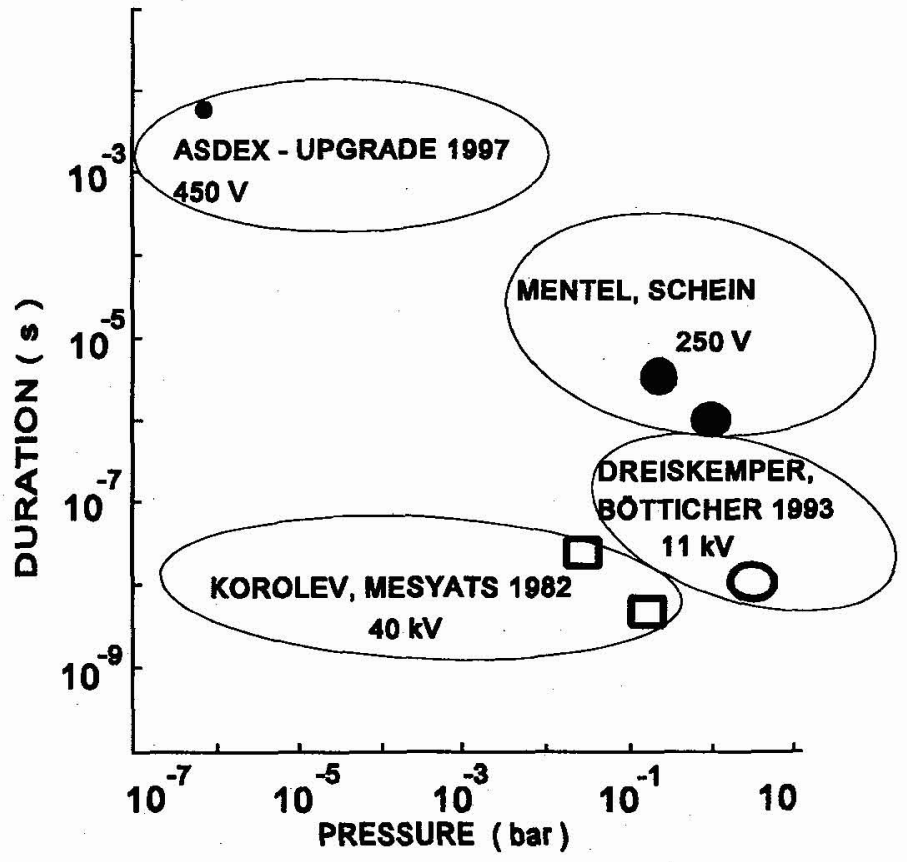

Fig. 21: Duration of predischarges as a function of pressure and voltage [24, 27-29] 
the emission. This effect of ion-field or ion-thermo-field emission has recently been studied by Testé and

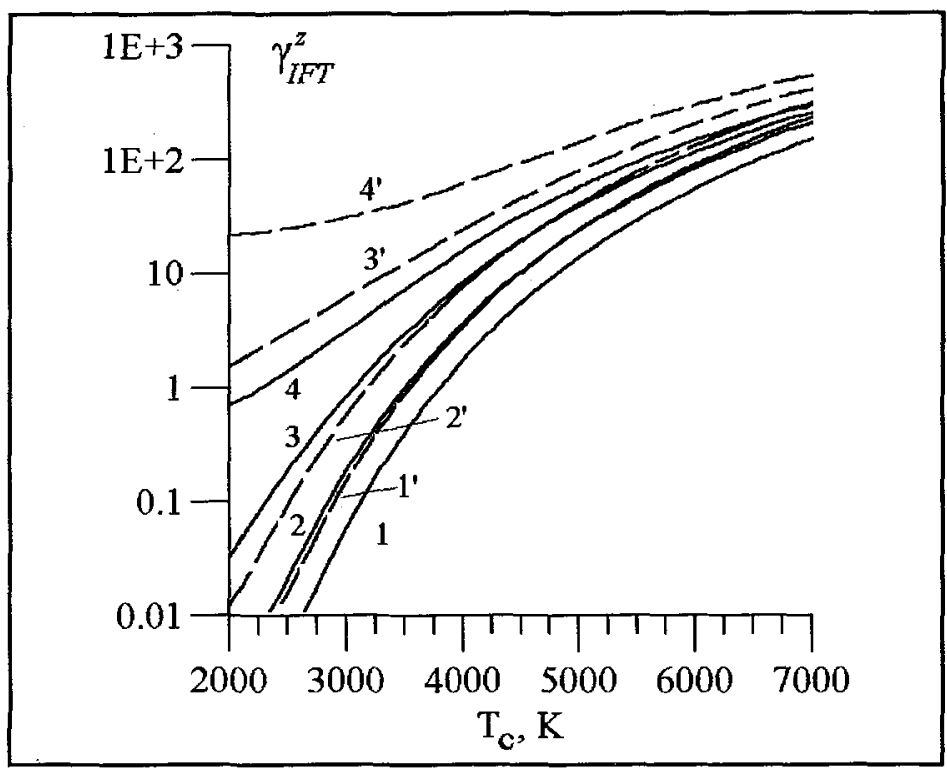

Fig. 22: Electron yield of I-F-T-emission as a function of the cathode temperature [34]. The numbers indicate the field strength: (1) $-2.5 \times 10^{8} \mathrm{~V} / \mathrm{m},(2)-5 \times 10^{8} \mathrm{~V} / \mathrm{m},(3)-1 \times 10^{9}$ $\mathrm{V} / \mathrm{m},(4)-1.5 \times 10^{9} \mathrm{~V} / \mathrm{m}$. Solid and dashed lines: ion charge number 1 and 2 , respectively
Chabrerie [33] and by Vasenin and co-workers [34]. Fig. 22 from ref. 34] shows the electron yield $\gamma_{\text {IFT }}^{z}$ caused by the effect in addition to thermo-field emission (number of electrons per ion with charge $z)$. As a consequence, in a plasma field emission is possible at smaller electric fields than in vacuum.

Hence, the ignition process can be assumed as follows: When the spot decays, transient voltages are developed that cause the formation of a sheath outside the center with high electric fields. Field electron emission enhanced by ion impact leads to surface explosions that produce new fragments within a nanosecond or less.

\section{CONCLUDING REMARKS}

The well known conception of fragments [35] promises to yield the key for the understanding of the cathode spots. Probably the nature of the fragments does not so much depend on the external conditions, while the variety of cathode spots will be due to varying combinations of fragments and different processes of their mutual interaction. To study the nature of the spot substructure, one needs spatial resolution $<10 \mu$ s and time resolution $<50 \mathrm{~ns}$, thus the present experimental devices are operating at the technical limit. In vacuum, and with clean surfaces, several fragments combine to a single spot that then reaches a size of about $50 \mu \mathrm{m}$. At atmospheric pressure the fragments remain separated, having a size too small to be resolved yet. In the past it has often been argued that the spot must be much greater than a surface crater [36], the latter having diameters of a few $\mu \mathrm{m}$, but now it turns out that the size of the fragment plasma is even smaller than the crater.

In vacuum the formation and residence time of the fragments are below the available resolution. Probable values are of the order of $1 \mathrm{~ns}$. The fragment ensemble as a whole that forms the spot is slower, though in vacuum time constants $<50 \mathrm{~ns}$ could be observed for the whole spot (compare fig. 7). This supports the concept of cyclic reproduction on a nanosecond timescale as proposed by Mesyats (ECTONS), though the base process is not necessarily an explosion, because to evaporate a piece of matter with a size of $1 \mu \mathrm{m}$ a time of $10 \mathrm{~ns}$ is sufficient. The explosion models have a long history, starting with Rothstein in 1948 [15] and Nekrashevich and Bakuto in 1955 [37]. The further development is marked by Fursey and co-workers [38], Mitterauer [39], and Mesyats and co-workers [14, 40]. However, these models are often hypothetical, and many physicists and engineers have doubts that the seemingly stationary discharges are composed of short individual acts. So they admit nanosecond processes as a phenomenon of ignition at the highest. More research is needed to clarify the relevance of nanosecond spots in gases and with hot cathodes, but for cold cathodes in vacuum they have always been found in our experiments. 
The existence of nanosecond fragments promises the understanding of the paradoxical behavior of the arc spot: Why does it move to cold locations, why the direction is retrograde in a magnetic field, why external gas with pressures far below the spot pressure can influence the movement, what are the forces that repel the spots from each other? The answer could be: there are no repelling forces, only the attracting Lorentz-force, the movement being due to a loss of symmetry in the fragment configuration as indicated in fig. 17. It is hoped to test this idea in near future.

If the cyclic nature is true, the ignition processes deserve more attention. Here the experiments in Bochum [24, 25] and the theory in Toulouse [30] and Hannover [31] yielded valuable results, especially with respect to the formation of transient plasma sheaths. It must still be examined whether this can be generalised to the high pressure metal vapor plasma of the cathode spots. There is already some experimental evidence that the surface in the neighbourhood of a spot can be modified by intense ion bombardement [41], in analogy to fig. 19.

In spite of the experimental progress of the recent years, we are but at the beginning to understand the vapor producing spots. At present it seems hopeless to develop theoretical models where the properties of the spots can be calculated from their interconnection with the other parts of the discharge without introducing empirical data, in contrast to the situation with quasistationary spots on hot cathodes [1-8]. However, there may exist mixed cases: vacuum arc spots can become more stationary when the cathode is sufficiently hot or when they are anchored at special surface structures as for example in the work of Djakov $[42,43]$, and transient microspots can occasionally be found at thermionic cathodes (fig. 15).

\section{Acknowledgements}

The author is indebted to the Deutsche Forschungsgemeinschaft for the grants Ju 227/5-1 and Ju 227/7-1; to the Bundesministerium für Bildung und Forschung for the grants $13 \mathrm{~N} 6616$ and 13N7108/1; and to E. Hantzsche, Berlin, and B. E. Djakov, Sofia, for helpful comments. Also, he thanks the referees for stressing the importance of spots on hot cathodes and suggesting to discuss the work of Siemroth et al. [21].

\section{References}

[1] Delalondre, C: and Simonin O. J., Physique Coll. 51 (1990) 199-206.

[2] Zhu, P., Lowke, J. J., and Morrow, R., J. Phys. D: Appl. Phys. 25 (1992) 1221-30.

[3] Morrow, R. and Lowke, J. J., J. Phys. D: Appl. Phys. 26 (1993) 634-642.

[4] Zhu, P. and Lowke, J. J. R., J. Phys. D: Appl. Phys. 26 (1993) 1073-1076.

[5] Kaddani, A., "Modélisations 2D and 3D des Arcs Electriques dans l'Argon à la Pression Atmosphérique avec la prise en compte du Couplage Thermique et Electrique Arc-Electrodes et de l'Influence des Vapeurs Métalliques", Thesis Paris 1995, also Report EDF HE-44/95/012/A.

[6] Benilov, M. S. and Marotta, A., J. Phys. D: Appl. Phys. 28 (1995) 1869-1882.

[7] Lowke, J. J., Morrow, R., and Haidar, J., J. Phys. D: Appl. Phys. 30 (1997) 2033-2042.

[8] Rethfeld, B., Wendelstorf, J., Klein, T., and Simon, G., J. Phys. D: Appl. Phys. 29 (1996) 121-128.

[9] Hantzsche, E., "Theories of Cathode Spots" in: Handbook of Vacuum Arc Science and Technology, Eds.

Boxman, R. L., Martin, P. J., and Sanders, D. M., (NOYES Publications New Jersey 1995), pp. 151-208. [10] Ecker, G., "Theoretical Aspects of the Vacuum Arc" in: Vacuum Arc. Theory and Application, Ed. Lafferty, J. M. (Wiley NY 1980), pp. 228-320.

[11] Beilis, I., "Theoretical Modeling of Cathode Spot Phenomena" in: Handbook of Vacuum Arc Science and Technology, Eds. Boxman, R. L., Martin, P. J, and Sanders, D. M., (NOYES Publications New Jersey 1995), pp. 208-264.

[12] Drouet, M. G., and Meunier, J. L., IEEE Trans. Plasma Sci. PS-13 (1985) 285-287.

[13] Beilis I., Djakov B. E., Jüttner B., and Pursch, H., J. Phys. D: Appl. Phys. 30 (1997) 119 -130.

[14] Mesyats, G. A., "Properties of ectons in a vacuum discharge", XVth Int. Symp. Discharges and Electr. Insul. in Vacuum, Ed. Mesyats, G. A. (SPIE vol. 2259, Washington 1994), pp. 22-29. 
[15] Rothstein, J., Phys. Rev. 73 (1948) 1214.

[16] Hantzsche E., Jüttner, B., and Ziegenhagen, G., IEEE Trans. Plasma Sci. 23 (1995) 55-64.

[17] Jüttner, B., J. Phys. D: Appl. Phys. 28 (1995) 516-522.

[18] Jüttner, B., J. Phys. D: Appl. Phys. 30 (1997) 221-229.

[19] Anders, A., Anders S., Jüttner, B., Bötticher, W., Lück, H., and Schröder, G., IEEE Trans. Plasma Sci. 20 (1992) 466-472.

[20] Vogel, N. and Skvortsov, V., XVIlth Int. Symp. Discharges and Electr. Insul. in Vacuum, Eds. Anders, A. and Anders, S. (LBL Berkeley 1996), pp. 89-98.

[21] Siemroth, P., Schülke, T., and Witke, T., IEEE Trans. Plasma Sci. 23 (1995) 919-925.

[22] Vogel, N., private communication.

[23] Frank, K., Felsner, P., Christiansen, J., Hintz, G., Mehr, T., Prucker, U., Stenzenberger, J., Stetter, M., Tkotz, R., and Hoffmann, D. H. H., XVIIth Int. Symp. Discharges and Electr. Insul. in Vacuum, Eds. Anders, A. and Anders, S. (LBL Berkeley 1996), pp. 1029-1033.

[24] Schein, J., Schumann, M., Nandelstädt, D., and Mentel, J., IEEE Trans. Plasma Sci. 25 (1997), to be published

[25] Nachtigall, K. P. and Mentel, J., IEEE Trans. Plasma Sci. 19 (1991) 947-953.

[26] Ertl, K. and Jüttner, B., Nuclear Fusion 25 (1985) 1413-1419.

[27] Jüttner, B., "Electrical Breakdown and Arcs in a Tokamak", unpublished report, Berlin 1997.

[28] Dreiskemper; R., Schröder, G., and Bötticher, W., IEEE Trans. Plasma Sci. 23 (1995) 180-187.

[29] Korolev, Yu. D. and Mesyats, G. A., "Field Emission and Explosive Processes in a Gas Discharge",

Ed.Koval'chuk, B. M. (Nauka Publishers Novosibirsk 1982).

[30] Belasri, A., Boeuf, J. P., and Pitchford, L. C., J. Appl. Phys. 74 (1993) 1553-1567

[31] Simon, G. and Bötticher W., J. Appl. Phys. 76 (1994) 5036-5046

[32] Jimenez, M., Noer, R. J., Jouvet, G., Jodet, J., and Bonin, B., J. Phys. D: Appl. Phys. 27 (1994) 10381045.

[33] Testé, P. and Chabrerie, J. P., J. Phys. D: Appl. Phys. 29 (1996) 697-705

[34] Vasenin, Yu. L., Gvozdetsky, V. S., Krivtsun, I. V., Zel'nichenko, A. T., Vladimirov, V. V., Jüttner, B., and Pursch, H., "Theory of the cathodic region of electric arcs in vacuum", Report BMBF 13N6616 (Berlin 1997).

[35] Kesaev, I. G., "Cathode processes of an electric arc" (Nauka Publishers Moscow 1968).

[36] Rakhovsky, V. I., IEEE Trans. Plasma Sci. 4 (1976) 81-102.

[37] Nekrashevich, I. G., and Bakuto, I. A., Bull. Byelorussian Acad. Sci., Phys. Techn. Inst. 2 (1955) 167177.

[38] Fursey, G. N. and Vorontsov-Vel'yaminov, P. N., Sov. Phys.-Tech. Phys. 12 (1967) 1370-1382.

[39] Mitterauer, J., Acta Physica Austriaca 37 (1973) 175-192.

[40] Bugaev, S. P., Litvinov, E. A., Mesyats, G. A., and Proskurovsky, Sov. Phys. Usp. 18 (1975) 51-61.

[41] Puchkarev, V. F. and Bochkarev, M. B., XVth Int. Symp. Discharges and Electr. Insul. in Vacuum, Ed.

König, D. (VDE Verlag Berlin 1992), pp. 359-363.

[42] Djakov, B. E., Contrib. Plasma Phys. 33 (1993) 201-207.

[43] Djakov, B. E., Contrib. Plasma Phys. 33 (1993) 307-316. 